\title{
CUIDADO Y RESPONSABILIDAD: DE HANS JONAS A CAROL GILLIGAN ${ }^{1}$
}

\author{
AGUSTÍN DOMINGO MORATALLA \\ UIMP, Universidad de Valencia
}

\begin{abstract}
RESUMEN: El objetivo de este trabajo es situar la ética del cuidado en contexto de las éticas de la responsabilidad. Para ello analizamos la orientación hacia el cuidado en las éticas de la responsabilidad mostrando la transición de una responsabilidad limitada por el cálculo consecuencialista en la actividad política, a una responsabilidad integral exigida por la preservación de la naturaleza ante los desafíos de la ciencia y la técnica. Interpretamos la aportación de Carol Gilligan en términos de «provocación» a la ética contemporánea para que el cuidado no sea únicamente una categoría sentimental o afectiva sino una categoría con la que reconstruir reflexivamente la justicia social. Esta interpretación evita que la orientación al cuidado se reduzca a una introducción del género en la ética de la justicia y minusvalore el papel de la fundamentación en detrimento del activismo. Este fortalecimiento el cuidado de la responsabilidad resulta fecundo si leemos a Gilligan desde Hans Jonas. Se construye así una responsabilidad sustantiva e integral que levanta la «VOz» y se convierte en grito para romper con el descuido, la indiferencia y la insensibilidad.
\end{abstract}

PALABRAS CLAVE: Ética; cuidado; responsabilidad; naturaleza; diferencia; lenguaje; comunicación; ecología; feminismo; ecofeminismo; antropocentrismo; personalismo.

\section{Care and responsibility: from Hans Jonas to Carol Gilligan}

ABSTRACT: The objective of this work is to place the ethics of care in the context of the ethics of responsibility. For this we analyze the orientation towards care in the ethics of responsibility, showing the transition from a limited responsibility for the consequentialist calculation in political activity, to an integral responsibility required by the preservation of nature in the face of the challenges of science and technique. We interpret the contribution of Carol Gilligan in terms of «provocation» to contemporary ethics so that care is not only a sentimental or affective category but a category with which reflexively reconstruct social justice. This interpretation avoids that care orientation be reduced to an introduction of gender in the ethics of justice and underestimates the role of the foundation to the detriment of activism. This strengthening the care of responsibility is fruitful if we read Gilligan from Hans Jonas. Thus a substantive and integral responsibility is constructed that raises the «voice» and becomes a cry to break with carelessness, indifference and insensitivity.

KEY WORDS: Ethics; care; responsibility; nature; difference; language; communication; ecology; feminism; ecofeminism; anthropocentrism; personalism.

\section{Cuidado y Responsabilidad}

\section{a. Una progresiva orientación al cuidado}

El concepto de cuidado se ha convertido en uno de los términos más importantes de la Ética y, sobre todo, de la Bioética contemporánea. Junto

1 Este estudio se inserta en el Proyecto de Investigación Científica y Desarrollo Tecnológico FFI2016-76753-C2-1-P, financiado por el Ministerio de Economía y Competitividad, y en las actividades del grupo de investigación de excelencia PROMETEO II/2014/082 de la Generalitat Valenciana. También se enmarca en el Proyecto de investigación: «La condición humana ante los retos de la Ecología» de la Cátedra Francisco José Ayala de Ciencia, Tecnología y Religión de la Universidad Pontificia Comillas (2016-2019) 
al modelo tradicional de Bioética «principialista» hoy podemos hablar de una «Bioética del cuidado»². La expresión debe mucho a las diferentes reconstrucciones de la razón práctica que se han producido en el pensamiento contemporáneo después del raciovitalismo, la fenomenología y la hermenéutica. De hecho, sin el concepto de una razón «vital», sin el protagonismo reflexivo de la existencia «fáctica» y sin la centralidad del «tú» o la vulnerabilidad y alteridad en el personalismo dialógico, no se hubiera producido esta orientación hacia el cuidado. Estas aportaciones nos recuerdan la necesidad de trabajar con un modelo de razón práctica renovada cuyo horizonte no puede ser únicamente el racionalista de una «razón pura» sino el raciovitalista, narrativo y cordial de una «razón impura».

Esta orientación hacia el cuidado se ha producido de una manera progresiva como resultado de un proceso donde la razón práctica se ha resistido a ser analizada en términos de fría razón pura y alza la voz para ser re-pensada desde la vulnerabilidad, fragilidad y, en general, el orden de los afectos, las emociones y las pasiones. Podríamos reconstruir el concepto de cuidado y descubriríamos un potencial reflexivo olvidado que está empezando a recuperarse. Incluso podríamos acudir al papel que San Agustín y Sören Kierkegaard tienen en el análisis existencial de la "cura» (sorge) de Heidegger para considerar esta centralidad del cuidado en la filosofía contemporánea. Una centralidad que, si bien no se ha olvidado, no ha recibido el análisis explícito que hoy se merece. Y eso sin contar con la posibilidad focalizar el campo semántico del cuidado a las actividades relacionadas con el cuidado explícito de la salud. Precisamente, desde este campo de la salud y la atención sanitaria en general, la centralidad del cuidado se ha convertido en una apasionante tarea moral en la era del dominio planetario de la ciencia y la técnica. ${ }^{3}$

De la misma manera que el mundo-de-la-vida era un contra-concepto en la filosofía de Husserl, el cuidado se ha convertido en un contraconcepto no sólo en el campo de la salud sino en el campo de la acción social y política. La aparición de programas de "humanización» de la atención sanitaria, el desarrollo de la psicología humanista y la emergencia de la psicoterapia, pueden interpretarse como respuestas orientadas por el cuidado. ${ }^{4}$ Además del ámbito socio-sanitario, el conjunto de las políticas públicas no sólo se gestionan en términos de crecimiento y desarrollo sino en términos de cuidado. ${ }^{5}$ Sin este horizonte sería inexplicable la aparición del concepto de sostenibilidad en el conjunto de la política pública y los objetivos para el desarrollo sostenible de Naciones Unidas (ODS). Este amplio alcance del que hoy goza el concepto de cuidado no puede ser interpretado únicamente en términos de reconstrucción

2 Lopez Alonso, M., El Cuidado. Un imperativo para la Bioética, Universidad Pontificia Comillas, Madrid 2011.

3 Brugere, F., L'éthique du «care», Puf, Paris 2011.

4 Bermejo, J.C., Counselling humanista, San Pablo, Madrid 2018.

5 Cfr. Domingo, A., Ética y Voluntariado. Una solidaridad sin fronteras, PPC, Madrid $2002,2^{\mathrm{a}}$ ed. 
o deconstrucción de los mimbres principialistas de la razón científico-técnica (obligado y necesario ejercicio de memoria), sino como emergencia del innovador paradigma de la responsabilidad.

\section{b. Responsabilidad y comunicación humana}

Este paradigma de la responsabilidad se ha consolidado de manera progresiva en la ética filosófica del siglo XX en tres momentos. El primero podemos situarlo en la conferencia de Max Weber sobre la política como vocación, recogida en el libro que lleva por título El político y el científico (realizada en 1919) ${ }^{6}$. En el ejercicio de la política y, sobre todo, en los procesos de comunicación que nutren la legitimidad racional (a diferencia de la tradicional o carismática) de las decisiones políticas, es decir, de los procesos de argumentación, deliberación y justificación, emerge la ética de la responsabilidad. Entre la ética de la convicción y la ausencia de ética, Weber sitúa la ética de la responsabilidad.

Mientras que en la ética de la convicción se descuidan las consecuencias porque se atiende a los principios, el modelo de la responsabilidad atiende, se preocupa y cuida de las consecuencias de los actos. Más que un modelo estrictamente consecuencialista, Weber nos sitúa ante una ética basada en una razón juiciosa, calculadora de las consecuencias y circunstancias de la acción, preocupada por las modificaciones institucionales de la realidad y, en cierta medida, en una ética del cuidado entendido como discernimiento, vigilancia, prudencia, ponderación y precaución. ${ }^{7}$

Hay un segundo momento que podemos localizar con la aparición del libro La transformación de la Filosofía de Karl Otto Apel (publicado en 1973). En este caso, la responsabilidad aparece como resultado del giro lingüístico, hermenéutico y aplicado de la filosofía para atender y cuidar el horizonte de verdad en la comunicación humana. Con ello, la responsabilidad no viene exigida sólo por una determinada praxis (como en el caso de Weber, la política) sino por la estructura dialógica de toda la comunicación humana, lo que supone una extensión de la responsabilidad a todas las actividades humanas y, en general, a todos los ámbitos del conocimiento.

No se trata de una responsabilidad teórica o especulativa, tampoco técnica o instrumental. Se trata de una responsabilidad nueva y referida al conjunto de todas las actividades y que no viene exigida por el paradigma de la filosofía del «ser» o la «conciencia» sino por el paradigma de la «comunicación». Aprovechando las aportaciones de Gadamer sobre la estructura dialógica del lenguaje ${ }^{8}$, Apel describe esta responsabilidad como dialógica y comunicativa. Aplicado a la comunicación humana, también nos encontramos ante una cierta ética del cuidado entendido como atención, preservación y mantenimiento

\footnotetext{
Weber, W., El Político y el científico, Alianza, Madrid 2017, $18^{\mathrm{a}}$ ed.

Gracia, D., La cuestión del valor, RACMP, Madrid 2011, p. 149.

Domingo, A., El arte de poder no tener razón. La hermenéutica dialógica de Gadamer, Ediciones de la Univ. Pontificia Salamanca, Salamanca 1990.
} 
de los presupuestos de sentido que hacen posible la comunicación humana. En este caso, además de atender las circunstancias históricas y cuidar las consecuencias de la acción, ahora es necesario aplicar el cuidado al logos compartido o comunicación que somos.

\section{c. De la responsabilidad contractual a la responsabilidad integral}

Pocos años más tarde de que apareciera el segundo volumen de la Transformación de la Filosofía de K. O. Apel, Hans Jonas recoge un conjunto de trabajos publicados con anterioridad que llevarán el título «El principio de responsabilidad. Ensayo de una ética para la civilización tecnológica» ${ }^{9}$. Si la comunicación era importante para K. O. Apel, para H. Jonas será la naturaleza. El poder que ha ido consiguiendo el ser humano durante los últimos siglos y, sobre todo, durante las últimas décadas, ha puesto el conjunto de la naturaleza a su disposición. Mientras que el poder anterior sobre la naturaleza era limitado y las «heridas» que le causaba podían ser reparadas con pequeñas intervenciones, ahora la propia especie humana se ha convertido en una amenaza para la continuación de la vida en la tierra.

La responsabilidad no es una opción o una posibilidad que se le ofrece al ser humano hoy, sino una obligación reclamada por un nuevo imperativo de un nivel similar al kantiano o de alcance aún mayor. Ahora el ser humano no sólo puede acabar con su propia existencia o la de su generación, sino que puede acabar con su propia esencia y desfigurarla con diversas manipulaciones. Ninguna ética anterior se vio ante los desafíos que las actuales ciencias de la vida han planteado al ser humano y ha llegado el momento de que la ética no se oriente hacia el pasado (atender consecuencias) o el presente (prevenir consecuencias) sino hacia el futuro (anticipar las consecuencias). Si el hombre antes podía «curar» o reparar la naturaleza, ahora está obligado a "cuidarla». La responsabilidad no puede ser sólo retrospectiva (orientada por el pasado o respectiva (orientada por el presente), tiene que res prospectiva (orientada por el futuro).

En palabras de Jonas, «Responsabilidad es el cuidado, reconocido como deber, por otro ser, cuidado que, dada la amenaza de su vulnerabilidad, se convierte en «preocupación» ${ }^{10}$. Como ha señalado acertadamente Tomás Domingo, hemos pasado de la «experiencia» de la fragilidad en las éticas anteriores, a la «exigencia» de la responsabilidad ${ }^{11}$. Si leemos con detalle el conjunto de la

9 Jonas, H., El principio responsabilidad, Círculo de Lectores, Barcelona 1994. Trad. De A. Sánchez Pascual.

10 Jonas, H., op. cit., p. 357, subrayado del autor.

11 Domingo, T., «De la experiencia de fragilidad a la exigencia de responsabilidad» en: Crítica, 980 (2012) 35-38. Del mismo autor, cfr. H. Jonas: Una ética de la responsabilidad, Grin, Múnich, 2014; «El mundo en nuestras manos. La ética antropológica de Hans Jonas» en: Diálogo Filosófico, 49 (2001) 37-60; «La ética antropológica de Hans Jonas en el horizonte de la fenomenología hermenéutica» en: Themata. Revista de Filosofía, 39 (2007) 373-380. 
obra de Jonas comprobamos que estamos ante una «responsabilidad» que no se limita a ser estrictamente moral, legal, civil o penal, y que podemos calificar como integral, es decir, una responsabilidad que no se limita a la esfera humana sino que incorpora el bien de las cosas extrahumanas:

«Habría de buscarse no sólo el bien humano, sino también el bien de las cosas extrahumanas, esto es, implicaría ampliar el reconocimiento a "fines en sí mismos" más allá de la esfera humana e incorporar al concepto de bien humano el cuidado de ellos.»12

Esta forma de entender al cuidado supondrá un cambio radical en la orientación antropocéntrica de la ética, y no se trata sólo de rectificarla o corregirla, sino de continuar la transformación iniciada con una orientación que podría ser calificada ingenuamente como biocéntrica o ecocéntrica. Ahora bien, deberíamos evitar planteamientos estrictamente biologicistas o naturalistas, como si rompiéramos las amarras con todas las formas de antropocentrismo y nos dispusiéramos a navegar por las indiferenciadas aguas del biocentrismo, el ecocentrismo o el medioambientalismo. No se trata de romper amarras o simplemente cambiar de orientación, se trata de corregir, rectificar y revisar las orientaciones antropocéntricas.

En este sentido, no se trata de abandonar la orientación antropocéntrica o las tradiciones humanistas en las que hunde sus raíces una cultura de la responsabilidad, sino de repensar vital y ecológicamente el nuevo puesto del hombre en el cosmos. En terminología de J. Gómez Caffarena podríamos decir que Hans Jonas ha contribuido a desinstalar o descentrar un enfoque estrictamente antropocéntrico para la ética, esto es, nos puede ayudar a pensar el papel del ser humano en el conjunto de la naturaleza (no solo del «medio ambiente»), la sociedad y la historia ${ }^{13}$. Se trataría de plantear el puesto del hombre en el cosmos con la paradójica expresión de "centro descentrado" para evitar cualquier ingenua o fácil navegación en aguas biologicistas, naturalistas o medioambientalistas. Si hablamos de biocentrismo o ecocentrismo en la propuesta de Jonas debemos dejar claro que no es «ingenuo» sino post-crítico o reflexivo. Más preciso sería describir esta apelación al cuidado como una orienación «bio/eco-antropo-céntrica» y no sólo biocéntrica o ecocéntrica. No olvidemos que la existencia de la humanidad es «el primer mandamiento». ${ }^{14}$

Si leemos con detalle los textos de Jonas podemos describir su posición en términos de «responsabilidad integral». Deja muy claro que necesitamos una transformación de la responsabilidad que no se limite a los tradicionales planteamientos horizontales o contractualistas sino que integre la verticalidad intergeneracional y la naturaleza. Con ello nos acercamos a una responsabilidad que extiende su cuidado al conjunto de la sociedad, la

12 Jonas, H., op. cit., p. 35, subrayado nuestro.

13 Cfr. Gomez Caffarena, J., La entraña humanista del cristianismo, Desclée de Brower, Madrid 1986; El enigma y el Misterio, Trotta, Madrid 2007.

14 Jonas, H., op. cit., p. 173. 
naturaleza y la historia (futuras generaciones). Lo más fácil sería dejarnos seducir por el temple biocéntrico y naturalista de Jonas para recuperar, de nuevo, la dimensión biológica y espontánea de la vida humana. Sería como romper la tensión, equilibrio y potencial conceptual que hay en la expresión centro-descentrado y dejar de replantear el puesto del hombre en el cosmos. $\mathrm{El}$ adjetivo «integral» nos recuerda precisamente la necesidad de cuidar de la naturaleza sin descuidar la humanidad y, también, de cuidar se la humanidad sin descuidar la naturaleza.

Esta responsabilidad integral supone una ética que no se desentiende de la religión ni de la metafísica. En términos de Jonas:

«A excepción de la religión, ninguna ética anterior nos ha preparado para el papel de fiduciarios; y menos aún nos ha preparado para ello la visión científica hoy dominante de la naturaleza. Esta visión, nos niega decididamente cualquier derecho teórico a pensar en la naturaleza como algo que haya de ser respetado, pues la ha reducido a la indiferenciación de casualidad y necesidad, y la ha despojado de la dignidad de los fines. Y, sin embargo, de la amenazada plenitud del mundo de la vida parece surgir una sorda llamada al respeto de su integridad. ¿Debemos escucharla?, ¿debemos reconocer su exigencia como vinculante, puesto que está sancionada por la naturaleza de las cosas, o bien no ver en ella más que un sentimiento nuestro al que, si lo deseamos, bien podemos abandonarnos siempre que podamos permitírnoslo? La primera alternativa, si se toman en serio sus implicaciones teóricas, nos obligaría a ampliar mucho más el mencionado cambio de ideas y pasar de la doctrina a la acción, esto es, de la ética, a la doctrina del ser, esto es, a la metafísica, en la que toda ética ha de fundarse en último término.» ${ }^{15}$.

Frente a un concepto puramente formal de responsabilidad, Jonas reclama una responsabilidad sustancial, basada en la bondad propia y reconocida de la cosa: «...bondad que afecta a la sensibilidad y abochorna al puro egoísmo del poder» ${ }^{16}$. Orientada por este horizonte de bondad «propia» y «reconocida» (no arbitraria o convencional), esta responsabilidad sustancial afecta al conjunto de vida, es decir, a la naturaleza y al ser humano, no es formal o vacía de contenido. No estamos ante una responsabilidad genérica o indeterminada sino una responsabilidad que se determina con el acto del agente moral:

«A esa especie de responsabilidad y de sentimiento de la responsabilidad, y no a la "responsabilidad" formal y vacía de todo agente por su acto, es a la que nos referimos cuando hablamos de ética, hoy necesaria, de la responsabilidad orientada al futuro...La mejor manera de acercarnos empíricamente a este concepto sustancial de responsabilidad, concepto comprometido con fines, es preguntar ... qué es lo que puede querer decirse cuando se habla de "actuar irresponsable". Aquí hay que excluir cualquier sentido formalista de "irresponsable" en el sentido de carente de capacidad de responsabilidad y, por ello, no susceptible de ser hecho responsable...el ejercicio del poder sin

15 Ibid., p. 35.

16 Ibid., p. 164. 
la observancia del deber puede ser "irresponsable", es decir, constituye una ruptura de esa relación de fidelidad que es la responsabilidad... ${ }^{17}$.

\section{d. Ecos, voces y gritos para una responsabilidad integral}

Para percibir con toda radicalidad el significado de esta apelación a la responsabilidad sustancial debemos acercarnos al libro de Jonas (El principio de responsabilidad) como algo más que un ejercicio literario o intelectual. Los diferentes capítulos donde perfila sucesivamente su imperativo y nos describe el imperativo de la responsabilidad como cuidado tienen que ser leídos en clave de «provocación». Provocación en el sentido originario de generar reacción o respuesta, es decir, como ejercicio comunicativo de un lector al que se desea activar, despertar o provocar. Si hacemos el ejercicio de leer en voz alta el libro de Jonas descubrimos que no es un simple conjunto de ensayos sino un ejercicio de comunicación, de interpelación y de provocación con lector.

No resulta difícil analizar los diferentes capítulos llenos de preguntas y respuestas, llenos de conceptos que tienen que ser puestos entre comillas como si en la dicción tuvieran que ser diferenciados. Quizá se trata de una provocación al «mundo de la vida» desde el «mundo de la técnica» donde no estamos únicamente con metáforas que procedan el campo semántico del «ver» sino del «oir». Jonas se hace eco de la gravedad del problema y no quiere que las alarmas despertadas pasen desapercibidas. Por eso alza la voz y a veces la urgencia o insistencia de su nuevo imperativo tiene la forma de «grito».

Observemos en uno de los textos citados anteriormente cuando dice: «de la amenazada plenitud del mundo de la vida parece surgir una sorda llamada...». En un ejercicio de retórica planteado como diálogo con el lector, nos insiste: «¿debemos escucharla?». Con ello observamos que Jonas se ha decidido a levantar la voz y, en el contexto del pensamiento contemporáneo no cabe duda que ha sido contundente y original, que no ha tenido miedo a nadar contra corriente. Hoy, varias décadas después de la publicación de su provocador ensayo y después de acoger los trabajos de F. Fukuyama (La gran ruptura, 2000) o del propio J. Habermas (El futuro de la naturaleza humana, 2003), podemos decir que la propuesta ética de Jonas era una provocadora «voz diferente» en las últimas décadas del siglo XX.

Durante la década de los setenta, Hans Jonas no fue la única voz del panorama filosófico que proporcionaba nuevos mimbres para una ética de responsabilidad. En su reclamación de un concepto de responsabilidad que incluyera la categoría de cuidado no era la única voz del desierto cultural. Había otras voces diferentes que pueden ser recuperadas para construir una ética a la altura de nuestro tiempo, y no sólo desde la tradición de filosofía española como Zubiri y Marías en aquellos años. Podemos centrarnos en obras que precisamente se estaban gestando estos mismos años y nos ofrecieron filósofos como Paul Ricoeur

17 Ibid., p. 165. 
(Tiempo y Narración), Alasdair MacIntyre (Tras la virtud) o Charles Taylor (Las Fuentes del yo), obras complejas que se gestaron entre la década de los setenta y aparecieron en los ochenta. Sin embargo, voy a centrarme en una voz femenina que construye su propuesta en estos mismos años porque en 1982 publica un interesante ensayo sobre la ética del desarrollo moral que se popularizado con el título In a different Voice, traducido como «Una voz diferente».

Leídos de forma separada, los trabajos de Jonas, MacIntyre, Ricoeur, Taylor o Gilligan tienen una singularidad propia. Ahora bien, quizá ha llegado el momento de rastrear la aportación específica para consolidar las éticas de la responsabilidad y renovarlas desde el cuidado. Ninguno de ellos prescinde del horizonte comunicativo y cada una de sus propuestas tienen algo de provocativa. Por ahora, detengámonos en la «provocación» de Gilligan y veamos cómo su propuesta de una «ética del cuidado» también transforma la responsabilidad para que no sea pensada en términos únicamente formales o contractuales sino en clave sustancial e integral.

\section{HoRizonTES PARA UNA RESPONSABILIDAD INTEGRAL: EL LEGADO DE CAROL GILLIGAN}

\section{a. Leer a Carol Gilligan desde la razón cordial}

Con la pretensión de reconstruir el cognitivismo de Kohlberg en los estudios del desarrollo moral, Carol Gilligan reclama «una voz diferente», subtítulo del libro publicado en 1982. Aunque hoy lo conocemos por ese título, conviene recordar los avatares iniciales del título que, en la edición realizada en español era: «La moral y la teoría. Psicología del desarrollo femenino». La primera edición en francés tenía un título diferente: "Une si grande différence». Después de las primeras ediciones, el libro es conocido como Una voz diferente (citaremos como VD). Lo que en principio se planteó como una revisión de la teoría psicológica aplicada al desarrollo de las mujeres, terminó siendo un apreciado trabajo para que las ciencias sociales se reconstruyeran desde lo que, en tradición posheideggeriana, llamaríamos un «pensamiento de la diferencia». Una forma de pensar que había quedado en el olvido y donde la mujer era la protagonista. Este inicial trabajo de psicología del desarrollo moral se convirtió en una referencia obligada para reconstruir la filosofía socio-política feminista y reinventar todas las profesiones sanitarias, fundamentalmente la enfermería ${ }^{18}$.

Las investigaciones que se presentan en el trabajo no muestran una diferencia de capacidades entre niños y niñas sino una "perspectiva», "enfoque», o «VOZ» diferente. A diferencia de los niños, las niñas privilegian los vínculos, la responsabilidad en la proximidad y la situación concreta frente al universo de

18 Feito, L., Ética de la enfermería, San Pablo, Madrid 2005; ver también «La Ética del cuidado como modelo de la ética de la enfermería» en: Metas de la enfermería, 8:8 (2005) 14-18. 
los derechos, las abstracciones y las generalizaciones. Con esta reivindicación de «la diferencia» en el ámbito del desarrollo moral se revisan los cimientos de la epistemología moral cognitiva que asentaron Piaget y Kohlberg. No olvidemos que este último había sido maestro y compañero de Gilligan.

Estos planteamientos no buscan sustituir el cognitivismo de las teorías del desarrollo moral y, por consiguiente, la posibilidad de una fundamentación moderna, racional y universalista de la educación moral. Gilligan no quiere sustituir la ética de la justicia (y los derechos humanos) por una ética del cuidado (y las responsabilidades) sino revisar, rectificar y ampliar los horizontes de una razón «abstracta». Pasar de una razón «abstracta» o kantianamente entendida como «pura», a una razón "concreta» o «impura» que cuenta con la situación, el contexto, la inmediatez, la vulnerabilidad y la facticidad corporal de las personas ${ }^{19}$. Con ello, se recuperan para la psicología moral categorías que ya eran básicas en Nietzsche, Bergson, Ortega, García Morente, María Zambrano, Zubiri, Marías, Marcel, Ricoeur y Lévinas, por mentar sólo algunos autores que han reclamado una renovación de la racionalidad moderna. Estos autores también reivindican una «Voz diferente» dentro de la ética contemporánea porque consideran que la vulnerabilidad, la fragilidad, la atención, el cuidado y la responsabilidad son categorías fundamentales olvidadas por un enfoque homogeneizador y unidimensional de la razón moderna centrada, aparentemente, en el universalismo abstracto de los derechos.

Sin negar la legitimidad de la reconstrucción del legado de Gilligan que puede hacerse desde la teoría sociopolítica feminista o desde las éticas profesionales, hay también una reconstrucción del legado que puede hacerse desde lo que, apoyándonos en la tradición orteguiana, podemos llamar de razón cordial. Lo que no impide reconstrucciones desde una razón utópica o profética donde la «voz diferente» pueda ser un «apasionado o desgarrador grito». Con ello proponemos una lectura del legado que ofrece posibilidades para evitar no solo la pendiente resbaladiza del género, en la que terminan algunas teorías sociopolíticas de la diferencia, sino la minusvaloración de la «teoría» ética por el hecho de que Gilligan reivindica actividades vinculadas a un cuidado «inmediato».

\section{b. El olvido de la voz al recordar la diferencia}

Lo más fácil es entender la ética del cuidado de Gilligan como una ética nueva que incide en la diferencia, es decir, que recupera una visión femenina y consolida el feminismo como una propuesta sociopolítica innovadora. En la práctica sanitaria también es legítimo hacer esta lectura fácil de la ética del cuidado porque proporciona «VOZ» a unos profesionales diferentes a los que, hasta ahora aparen-

19 Sobre el concepto de «puro» en Kant, cfr. CubelLs, F., «El concepto de puro en Kant y su sentido epistemológico en la crítica de la razón práctica» en: Anales Valentinos 7:13 (1967) 1-178. A la luz de estas reflexiones debemos entender la interpretación que hace el profesor J. Conill de la razón en Ética hermenéutica, Tecnos, Madrid 2006, 2ª ed. 
temente la tenían. Con ello prestamos atención al concepto de «diferencia» y nos olvidamos del concepto de «Voz». La ética del cuidado no es una propuesta ética «diferente», como si lo importante estuviera en la recuperación de una ética que no fuera cerebral, cognitiva o puramente racional. Las lecturas más habituales de Gilligan recuerdan la «diferencia» pero se olvidan de la «voz», dejando a medias la interpretación auténtica de la novedad de Gilligan.

Además de leer con detalle su primera obra, en trabajos posteriores observamos que el verdadero valor de la ética del cuidado procede de la «voz diferente», no de la sola diferencia. Se trata de una recuperación hermenéutica radical y por ello también es básica la renovación del concepto de experiencia que propone Gilligan, como en su momento hizo el propio Gadamer ${ }^{20}$. En el libro editado por la Fundación Grifols y que lleva por título La Ética del Cuidado, encontramos varios textos que avalan esta interpretación de su propuesta. Por eso, la «voz diferente» es una voz de resistencia a las simplificaciones y, sobre todo, una voz de resistencia a las dualidades de género o las jerarquías patriarcales. No se trata solo de prestar atención a quienes son diferentes como tales sino a quienes, hasta ahora, no eran atendidos y escuchados, como si su voz hubiera estado olvidada.

La voz diferente es la voz de la humanidad más auténtica, es decir, una humanidad despojada de lastres culturales, tradicionales y patriarcales. En el corazón de la ética del cuidado está el anhelo de una humanidad más justa en la que todos los seres humanos puedan expresarse, se les pueda dejar hablar y su voz pueda ser reconocida:

«...el cuidado y la asistencia no son asuntos de mujeres: son intereses humanos... Con esta división de la moralidad por razón de género, la masculinidad ofrece fácilmente un pasaporte al descuido y la desatención, defendidos en nombre de los derechos y la libertad, mientras que la femineidad puede implicar una disposición a renunciar a derechos a fin de preservar a las relaciones y mantener la paz. Pero es absurdo sostener que los hombres no se interesan por los demás y que las mujeres no tienen sentido de la justicia. Identifiqué una voz diferente no a través del género sino del tema... la voz democrática expresa normas y valores democráticos: la importancia de que todos tengamos una voz... Las voces diferentes, en lugar de poner en peligro la igualdad, son imprescindibles para la vitalidad de una sociedad democrática... en absoluto era una voz limitada a las mujeres. En la cultura del patriarcado, tanto manifiesta como encubierta, la voz suena femenina...» $(\mathrm{DV}, 5 / \mathrm{G}, 54-55)^{21}$.

20 Sobre el concepto de «experiencia» en Gadamer puede verse: El arte de poder no tener razón. La hermenéutica dialógica de H. G. Gadamer, Ediciones de la Universidad Pontificia Salamanca, Salamanca 1989. También Conıll, J., Ética hermenéutica, op. cit., pp. 110-145.

21 A partir de ahora citaremos simultáneamente dos obras de Carol Gilligan: con las siglas DV citaremos primero el capítulo correspondiente de la obra clave La moral y la teoría. Psicología del desarrollo femenino, FCE, México 1985. En segundo lugar citaremos con la abreviatura G el libro La ética del cuidado, Fundación Grifols, Barcelona 2013. En este caso DV, 5/ G, 63 indica que estamos en el capítulo 5 de La moral y la teoría y la página 5 de La ética del cuidado. 
Hay una forma de pensar lastrada de tradiciones, patrones culturales y normas, que Gilligan califica como «cajones mentales dominantes». Frente a esa forma de pensar que califica como "patriarcalismo» y contrapone necesariamente a la «democracia», la ética del cuidado reivindica una teoría de la subjetividad y la moralidad que no encajan en los cajones mentales dominantes. La constatación de este desencaje, desadaptación o desinstalación en las tradiciones morales dominantes no puede ser interpretado como una limitación en el desarrollo moral:

"Comencé a trabajar en la ética del cuidado con el objetivo de descifrar las voces de las mujeres cuando sus conceptos del Yo y de la moralidad no encajaban en los cajones mentales dominantes. Quería demostrar que lo que se había calificado como debilidad propia de las mujeres o se había percibido como una limitación en su desarrollo, se podría interpretar en cambio como virtud humana.» (DV, 5/G,61).

Esta ética del cuidado debe tener capacidad para distinguir entre los diferentes modelos epidérmicos que hemos ido heredando culturalmente y un modelo de ética que busca la autenticidad. Cuando se refuerzan las diferencias de género nos olvidamos de la voz humana como tal, de lo que podríamos llamar en sentido estricto "punto de vista moral». Cuando los modelos heredados tienden a ser binarios y jerárquicos, entonces se reproduce un orden patricarcal contrario a unas fuentes de humanidad común y probablemente olvidada. La ética del cuidado apela a esta idea de humanidad común y en su camino se encuentra con categorías como las del amor y la ciudadanía democrática:

«Las diferencias de género en la voz moral no son producto de la naturaleza o de la crianza en sí, sino del modelo binario y jerárquico fundamental para el establecimiento y la conservación de un orden patriarcal. Los requisitos de amor y ciudadanía en una sociedad democrática son una misma cosa... Los psicólogos que estudiaron a los varones y generalizaron sus hallazgos a todos los humanos, o que enmarcaron sus teorías desde una perspectiva masculina, confundieron el patriarcado con la naturaleza.» (DV, 5/G,63).

La apelación a la autenticidad supondrá la recuperación de un concepto hermenéutico de experiencia. Cuando la ética del cuidado se construye en clave de autenticidad nos exige descubrir la tensión entre las fuentes del yo y el conjunto de construcciones sociales que lo ocultan. Unas construcciones sociales que a veces nos llevan a separar innecesariamente el cuerpo y alma, el pensamiento y emociones. La ética del cuidado exige distinguir entre la vida falsa y la vida auténtica, la vida que se deja llevar por las autoridades externas y la vida que recupera la originalidad o naturalidad de una interioridad propia. El hecho de que se identifique simplificadamente la vida falsa con la vida de la autoridad, el honor y la masculinidad, no es un obstáculo para reconocer que estamos ante una valiosa teoría de la conciencia moral como "voz»y experiencia originaria. Frente apelaciones al cuidado que pueden suponer promover una cultura de la abnegación, la resignación y la aceptación acrítica de las circunstancias, estamos ante un cuidado que en terminología agustiniana podríamos llamar «inquieto» y quizá «transcultural». (DV, 1/G.32) 
En la ética del cuidado hay una tensión entre dos voces, por un lado la voz de la autoridad y por otro la voz de la experiencia. Cuando no hay cuidado faltan elementos básicos y radicales de la vida moral: la atención, la integridad moral y el respeto. Un elemento básico que anteriormente había calificado escuetamente como «virtud» en el sentido más estoico de la palabra. Con sus propias palabras:

«la ética del cuidado nos guía para actuar con cuidado en el mundo humano y recalca el precio que supone la falta de cuidado: no prestar atención, no escuchar, estar ausente en vez de presente, no responder con integridad y respeto... (se trata de) revelar la humanidad propia de cada uno» $(\mathrm{DV}, 1 / \mathrm{G}, 34)$.

\section{c. Una estéril alternativa: curar versus cuidar}

Aunque la alternativa más inmediata es la que habitualmente establecemos en bioética cuando distinguimos entre curar (to cure) y cuidar (to care), o entre éticas de la justicia y éticas del cuidado, hay una alternativa inicial para entender la ética del cuidado de Gilligan. Me refiero a que la ética del cuidado se concreta en un conjunto de actividades o prácticas relacionales en las que parece que no es importante la teoría o el pensamiento, como si el cuidado fuera únicamente una actividad práctica e inmediata que no precisara «teoría». Puede parecer que las actividades relacionadas con el cuidar no necesitaran una fundamentación filosófica o una mediación reflexiva, que fueran intrascendentes, inmediatas y no necesitadas de análisis filosófico. Sin embargo, a medida que profundizamos en este ámbito del cuidar y lo planteamos en clave de responsabilidad, más necesidad tenemos de mediación reflexiva. ${ }^{22}$

En este sentido, lo que comenzó siendo una recuperación práctica e inmediata de las voces olvidadas de las mujeres, los marginados y los excluidos en los estudios del desarrollo moral, puede transformarse con Gilligan en una recuperación reflexiva y teórica innovadora. Por eso, la orientación de la ética contemporánea hacia el cuidado puede plantearse en términos de dinamización y activación de las tradicionales éticas de la justicia y el bien común. Sin el cuidado, nos descuidamos de la justicia, sin el principio de responsabilidad que vertebra la ética del cuidado corremos el peligro de que la ética de la justicia se reifique, rutinice o institucionalice en cálculo utilitario. ${ }^{23}$

22 Como hemos mostrado en otros trabajos, además de competencias técnicas y capacitación profesional, la ética del cuidado requiere también sensibilidad humana y capacidad de juicio o phronesis, cfr. El arte de cuidar: atender, dialogar y responder, Rialp, Madrid 2013. En este contexto teórico, I. Murdoch ha señalado que en la ética del cuidado no hay elecciones diferentes de una ética de la justicia sino una diferencia de visión, cfr. «Vision and choice in morality» en: Murdoch, I., Conradi, P. J. (ed.), Existencialists and Mystics: Writings on Philosophy and Literature, Chatto and Windus, Londres 1997.

${ }_{23}$ Ricoevr, P., Amor y Justicia, Caparrós, Madrid 1989, trad. de Tomás Domingo. Una aplicación de estos planteamientos se encuentra en nuestro trabajo Democracia y Caridad. Horizontes éticos para la donación y la responsabilidad, Sal Terrae, Santander 2016. 
Gilligan está pidiendo «a gritos» que escapemos de las estructuras binarias con las que habitualmente tiende a construirse la vida moral. Por ello la ética del cuidado no describe simplemente el conjunto de actividades que realizan las mujeres, sino el imperativo de romper con la indiferencia, el descuido y la insensibilidad moral básica. Cuidar es recuperar categorías éticas como la solicitud, la atención (care about), la afección-afectación (care for), la relación, la interdependencia o vulnerabilidad. A juicio de Gilligan:

«La ética del cuidado nos guía para actuar con cuidado en el mundo humano y recalca el precio que supone la falta de cuidado: no prestar atención, no escuchar, estar ausente en vez de presente, no responder con integridad y respeto...» (DV, 3/G, 34)

En estas páginas, cuando comenta determinados textos sobre la necesidad de superar las dialécticas basadas en la diferencia de amigo/enemigo, recuerda lo importante que es no cerrarse a ningún diálogo. Ella sostiene «yo hablaría con cualquiera porque no están hablando de negociar la paz, sino de algo más elemental. Se refiere a revelar la humanidad propia de cada uno» (G,34). Como han señalado algunos comentaristas de Gilligan, el llamado debate «cuidadojusticia» se produce en sentido único:

«Mientras que los partidarios de las teorías tradicionales de la justicia rechazan la ética del cuidado (care), prácticamente todos los partidarios del cuidado (care) reconocen sin dudar la centralidad de las consideraciones de la justicia para emitir juicios sobre la mejor forma de hacerse cargo de los otros. El cuidado (care) requiere de la justicia, pero requiere también que pensemos la justicia en el caso y las circunstancias concretas, no como un conjunto general de principios cuya aplicación se deja en manos de los tribunales, los políticos o los filósofos $\aleph^{24}$.

Desde la perspectiva de esta ética del cuidado, el sujeto moral y el próximo no están representados como entidades separadas, la relación y los vínculos humanos desempeñan un papel central. Para que esta ética no se limite al ámbito de la proximidad en los vínculos o de la vida privada, debe plantearse también en términos políticos. ¿Cómo hacer el paso de esta "ética del cuidado» a una "política de los cuidados»? Para responder a esta pregunta necesitamos reconfigurar el concepto de justicia de tal forma que las actividades y prácticas relacionadas con el cuidado constituyan el centro de una renovada teoría de la justicia social. ¿Alcanzaría a todas las actividades?,¿sería necesario una formalización y politización de todos los ámbitos del cuidado?

No es fácil responder a estas preguntas y por eso es importante no mantener la ética del cuidado únicamente en el ámbito de los sentimientos sino extenderla al mundo de las prácticas y las instituciones. Este paso no lo ha dado Carol Gilligan y nos llevaría a construir una antropología e incluso sociología de vulnerabilidad que no se desentienda de las necesidades y los cuidados con los

24 Tronto, J., Moral Boundaires. A political argument for an Ethic of Care, Routlegde, Londres/New York 1993. Prefacio a la edición francesa de 2009. 
que se afrontan. Como sostienen Laugier y Paperman, desde esta antropología de la vulnerabilidad deberíamos evitar la distinción entre un «cuidado emocional», atento a las necesidades afectivas de personas particulares, y un «cuidado de servicio» que puede ser delegado, formalizado y comprado ${ }^{25}$. Sin entrar por ahora en los correspondientes matices que se encuentran en este «cuidado de servicio» y los desafíos de la mercantilización, estas investigadoras reclaman unas políticas públicas que pongan el cuidado (care) en el centro de las prioridades políticas. En esta dirección, Fabienne Brugere ha llegado a reclamar la necesidad de una «democracia sensible». ${ }^{26}$

\section{d. Del ingenuo cuidado "femenino» al reflexivo cuidado "feminista»}

Gilligan ha conseguido que las actividades femeninas salieran a la luz y cobraran dignidad en los espacios públicos. La ética del cuidado y la recuperación del conjunto de actividades que realizan las mujeres también forman parte del espacio público y, por tanto, reclaman argumentación y deliberación pública. Lo que antes era visto como propio de un espacio privado y planteado epistemológicamente en términos de ingenuidad, ahora debe ser planteado en espacio público y en clave reflexiva. Al dar este paso estamos dando el salto de lo que hemos llamado un «ingenuo cuidado» aun "reflexivo cuidado». Desde aquí debemos entender la apelación y articulación del feminismo sociopolítico de Gilligan:

«La ética del cuiadado no es una ética femenina, sino feminista, y el feminismo guiado por la EC podría considerarse el movimiento de liberación más radical — en el sentido de que llega a la raíz— de la historia de la humanidad. Al desprenderse del modelo binario y jerárquico del género, el feminismo no es un asunto de mujeres, ni una batalla entre mujeres y hombres, sino el movimiento que liberará a la democracia del patriarcado» (DV, 1/ G, 31).

En la batalla de este feminismo, las referencias básicas están en los ejemplos de las mujeres buenas que encontramos en la historia. Y en ellas encontramos una virtud fundamental y básica también para la vida pública, la abnegación. Además, se inaugura de esta forma una posibilidad nueva de pensar la democracia recuperando el cuidado como capacidad humana natural:

«Cuidar es lo que hacen las mujeres buenas, y las personas que cuidan realizan una labor femenina: están consagradas al prójimo, pendientes de sus deseos y necesidades, atentas a sus preocupaciones; son abnegadas. En un contexto democrático, el cuidado es una ética humana. Cuidar es lo que hacen los seres humanos; cuidar de uno mismo y de los demás es una capacidad humana natural. La diferencia no estaba entre el cuidado y la justicia, entre las mujeres y los varones, sino entre la democracia y el patriarcado...» (DV,6/G,51).

25 Cfr. Laugier, S., Paperman, P., Le souci des outres, éthiques et politiques du care, EHESS, Paris 2005.

26 Cfr. Brugere, F., L' ethique du «care», PUF, Paris 2011, p. XXIX. 
Una verdadera ética del cuidado exige un nuevo cambio de paradigma en el conjunto de las ciencias sociales. Y no puede existir sin una transformación social, que es la meta del movimiento feminista, no concebido como "problema» mujeres/varones, sino como un "combate», planteado como uno de los grandes movimientos de liberación de la historia humana: «el movimiento para liberar la democracia del patriarcado». ${ }^{27}$

Sin entrar al detalle en las diferentes variantes del feminismo que se han abierto en las últimas décadas, cabe apuntar la responsabilidad que Gilligan también ha tenido en la aparición del ecofeminismo. Esta tradición filosófica integra la voz de las mujeres en el conjunto de la reflexión medioambiental. Y lo hace mostrando la vinculación entre la dominación a la que han sido sometidas las mujeres (propia del discurso feminista) y la dominación a la que ha sido sometida la naturaleza (propia del discurso medioambiental).

Esta visión femenina de las cuestiones ecológicas supone un abandono de la arrogancia del discurso masculino de «conquista de la naturaleza» y la sustitución por un discurso femenino de "cuidado de la naturaleza». La cuestión de la independencia de las mujeres que aparece en el movimiento feminista es, en otro nivel, de la misma que la independencia de la naturaleza de los planteamientos medioambientalistas. Entramos así en un conjunto de problemas que dejan la puerta abierta no sólo a la extensión de la ética del cuidado al conjunto de la naturaleza sino a una extensión de la ética del cuidado a los animales no humanos. Salimos de planteamientos antropocéntricos para entran en planteamientos ecocéntricos o biocéntricos. Aunque no se suprime la tensión propia de la reflexión antropológica del ser humano como centrodescentrado pero sí corremos el riesgo de que desaparezca la perspectiva personal, algo en lo que siempre hemos insistido cuando reclamamos la perspectiva de una ecología integral ${ }^{28}$. Como sostiene Catherine Larrére, el legado feminista de Gilligan puede ser una buena base para entrar en los debates éticos del nuevo «ecofeminismo» ${ }^{29}$

Así nos situamos a las puertas de una teoría general de cuidado que no sería únicamente una ética del cuidado. Con ello también podemos hablar en este contexto de un «cuidado integral» que articule no sólo la «diferencia» entre el ser humano, los animales y la naturaleza sino la «continuidad» o «discontinuidad» entre las especies. De esta forma, las «políticas del cuidado» no incluirían únicamente un "cuidado inmediato» de aquellos que son más próximos a nosotros sino un «cuidado global» que podría extenderse al conjunto de la naturaleza.

Siendo conscientes de lo limitado de este balance del legado ético de Gilligan, quizá sea bueno no dispersarnos en el conjunto de la naturaleza y fijarnos en esa

27 Gilligan, C., «Un regard prospectif à partir du passé» en: Nurock, V. (ed.), Carol Gilligan y l'éthique du care, PUF, Paris 2010, p. 37.

28 Hemos desarrollado estos planteamientos en Condición humana y ecología integral. Horizontes educativos para una ciudadanía global, PPC, Madrid 2017.

29 Cfr. Larrere, C., «Au-delà de l' humain: écofeminismes et éthique du care» en: Nurock, V., op. cit., pp. 151-174. 
«VOZ» a la que nos hemos remitido para no perder de vista que, lo que está en juego en la orientación hacia el cuidado es la posibilidad de plantear un cuidado reflexivo e integral reclamado por el «homo emphaticus» que, todavía, somos:

\begin{abstract}
«Necesitamos un debate nuevo sobre el género y sobre la ética... Ahora sabemos que el patriarcado deforma la naturaleza, tanto de las mujeres como de los varones, aunque de maneras distintas... Los hallazgos empíricos (neurociencias, etc.) convergen en un mismo punto convincente: somos, por naturaleza, homo empathicus en vez de homo lupus. La cooperación está programada en nuestros sistemas nerviosos: nuestros cerebros dan más luz cuando optamos por estrategias cooperativas que competitivas... En vez de plantearnos cómo adquirimos la capacidad de cuidar, nos preguntamos ¿Cómo perdemos nuestra humanidad?»(DV, 5/G,64-65).
\end{abstract}

\title{
ConcLusiones
}

Estos análisis sobre el legado de Gilligan a la ética contemporánea nos recuerdan que la reivindicación de una ética del cuidado supone una transformación de las éticas de la justicia. No estamos ante una alternativa a las éticas de la justicia sino ante la posibilidad de una transformación interesante y discutible. Discusión que puede iniciarse rastreando la presencia del cuidado en el ecologismo y el feminismo, pero que también puede rastreando el olvido de las políticas del cuidado en el conjunto de las políticas públicas del estado de bienestar.

Como hemos mostrado, el legado de Gilligan puede ser reconstruido desde el papel que la ética de la responsabilidad ha desempeñado en las éticas del siglo XX. Hemos señalado que la novedad de la ética del cuidado feminista puede ser planteada como una respuesta al principio de responsabilidad de Hans Jonas. Gilligan responde a la interpelación de Jonas y lo hace con la provocativa expresión "una voz diferente». No estamos ante una ingenua reivindicación de la diferencia sino ante una reflexiva reivindicación del poder de la palabra humana más vulnerable, frágil y sensible. Leída desde esta centralidad de la «VOZ», los ecos o gritos del feminismo en la ética contemporánea pueden tener un significado nuevo. Apuntan hacia un concepto de responsabilidad renovado por un cuidado integral. Una renovación en la que tendremos que plantearnos en algún momento cómo construir una ética del bien cuidar o de los «buenos cuidados». El horizonte sociopolítico de unas teorías de las democracias que establecen el cuidado en el corazón de su funcionamiento exigirá que, más bien antes que tarde, hagamos una fenomenología hermenéutica de los buenos cuidados.

El legado de Gilligan también nos permite situar el concepto de responsabilidad en el centro de los debates éticos contemporáneos, quizá como la clave de bóveda con la articular el debate entre antropocentrismo y bio/ecocentrismo. Como hemos mostrado en la primera parte del artículo la ética contemporánea ha extendido el significado de la responsabilidad y nos ha permitido pasar de 
una responsabilidad estrictamente legal (en cualquiera de sus versiones: civil, penal, patrimonial, etc.) a una responsabilidad global que nosotros hemos calificado como integral. Así conseguimos tres objetivos: plantear la responsabilidad en términos sustantivos (como nos reclamaba Jonas), ofrecer un renovado concepto de cuidado que no excluya su mediación reflexiva, teórica o crítica y presentar la urgente transformación de la filosofía como una "provocativa» llamada para reconstruir la ecología integral.

[Artículo aprobado para publicación en enero de 2019] 